Original Research Paper

\title{
Peningkatan Profesionalisme Guru melalui Peneltian Tindakan Kelas
}

\author{
Winarno $^{1^{*}}$ \\ ${ }^{1}$ Jurusan Pendidikan Bahasa Inggris FKIP Universitas Borneo Tarakan
}

https://doi.org/10.29303/jpmpi.v3i2.1215

Sitasi: Winarno. (2022). Peningkatan Profesionalisme Guru melalui Peneltian Tindakan Kelas. Jurnal Pengabdian

Magister Pendidikan IPA, 5(1)

\section{Article history}

Received: 10 Noveber 2021

Revised: 17 Desember 2021

Accepted: 30 Desember 2021

*Corresponding Author:

Winarno, Jurusan Pendidikan Bahasa Inggris FKIP

Universitas Borneo Tarakan,

Indonesia. Email:

Winarnovisit@gmail.com

\begin{abstract}
Karya tulis ilmiah merupakan salah satu persyaratan yang harus dipenuhi oleh guru ketika guru tersebut hendak mengajukan kenaikan pangkat seperti dari golongan IV/a ke IV/b, karya tulis ilmiah dapat berupa penelitian Tindakan kelas (PTK). Tujuan pengabdian ini adalah agar guru-guru mata pelajaran bahasa Inggris di kota Tarakan mempunyai kompetensi mengembangkan proposal penelitian tindakan kelas (PTK). Metode yang digunakan adalah pelatihan dan bimbingan melalui workshop. Guru-guru dilatih dan dibimbing menyusun proposal penelitian tindakan kelas (PTK). Kegiatan workshop memberikan manfaat bagi guru dalam mengatasi pemasalahan dalam menyusun proposal karya tulis ilmiah (PTK) yang dapat digunakan untuk memenuhi persyaratan kenaikan pangkat dan meningkatnya profesionalme guru. Subjek pengabdian ini adalah guru-guru mata pelajaran bahasa Inggris di Kota Tarakan yang tergabung dalam Forum Musyawarah Guru Mata Pelajaran (MGMP) Bahasa Inggris SMP di kota Tarakan. Workshop PTK dilaksanakan 3 hari di ruang pertemuan di SMP Negeri Tarakan. Hasil dari kegiatan ini adalah peserta workshop PTK mempunyai kompetensi dalam Menyusun dan menghasilkan proposal PTK. Kesimpulannya, kegiatan pelatihan terlaksana sesuai rencana, diperlukan intervensi dari pemangku kepentingan di bidang pendidikan agar profesionalisme guru melalui penelitian dapat terwujud.
\end{abstract}

Kata kunci : Tuna, siomay, income increase, diversification, partner participation

\section{Pendahuluan}

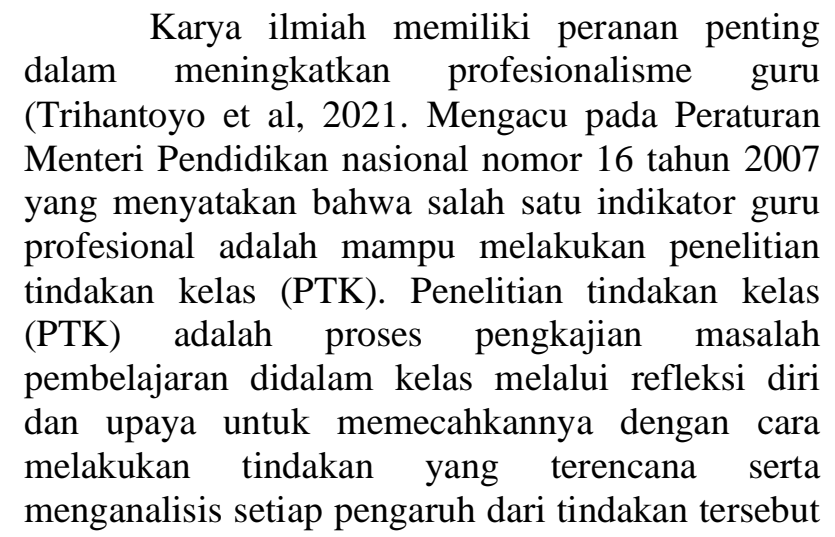

(Arikunto, 2010; Wijaya, 2013). Melalui penelitian tindakan kelas (PTK) dapat meningkatkan profesionalisme guru dan sekaligus dapat mengatasi permasalahan belajar siswa di kelas.

Forum musyawarah guru mata pelajaran (MGMP) merupakan suatu forum kegiatan profesional guru mata pelajaran sejenis yang berada pada satu sekolah, wilayah, kabupaten/kota, dan propinsi (Sumardi, 2016). Hasil wawancara dengan Ketua MGMP Bahasa Inggris SMP kota Tarakan, di tinjau dari sudut kepangkatan, sebagian besar guru memiliki permasalahan kenaikan pangkat guru khususnya dari golongan IV/a ke IV/b. Hal ini disebabkan kemampuan mereka dalam menghasilkan karya tulis masih lemah. Menurut 
Dharmayasa et al (2020) menghasilkan karya tulis menjadi salah satu syarat kenaikan pangkat. Kesulitan utama yang dihadapi para guru untuk naik pangkat adalah sulitnya mengumpulkan angka kredit pada komponen penulisan karya ilmiah. Sebagian besar guru bahasa Inggris SMP belum dapat menghasilkan karya ilmiah. Kemampuan menyusun karya tulis masih rendah. Rendahnya kemampuan menghasilkan karya tulis antara lain: (1) Beberapa guru telah mengikuti berbagai bentuk pelatihan penulisan karya ilmiah namun penerapannya lemah, (2) Guru mengalami kesulitan untuk menemukan ide dan gagasan untuk melaksanakan penelitian tindakan kelas, (3) Belum tercipta budaya akademik khususnya dalam penulisan karya tulis, (4) Belum muncul kesadaran guru untuk melakukan penelitian atau publikasi ilmiah.

FKIP Universitas Borneo Tarakan mempunyai dosen yang memiliki kemampuan yanglbaik dalam penyusunan karya tulis ilmiah atau melakukan penelitian khususnya penelitian tindakan kelas (PTK). Untuk membantu menyelesaikan persoalan yang dihadapi oleh guru maka dosen-dosen FKIP Universitas Borneo Tarakan menyusun kegiatan pengabdian pada masyarakat dalam bentuk workshop PTK bagi guru bahasa Inggris SMP di kota Tarakan.Workshop PTK yang diadakan oleh FKIP Universitas Borneo Tarakan sebagai bentuk kerjasama dengan Forum MGMP guru bahasa Inggris SMP di kota Tarakan melalui workshop (PTK). Hal tersebut bertujuan untuk melatih guru agar memiliki kompetensi dalam menyusun karya tulis dan mampu mengatasi permasalahan pembelajaran yang terjadi di kelas. Lebih lanjut, bermanfaat terhadap peningkatan profesionalisme guru dalam memperbaiki kualitas pembelajaran.

\section{Metode}

Metode kegiatan yang digunakan adalah metode ceramah, tanya jawab, diskusi dan juga bimbingan melalui kegiatan workshop. Workshop adalah kegiatan dimana dalam kegiatan tersebut terdapat orang-orang yang memiliki keahlian tertentu, berkumpul lalu membahas permasalahan dan memberi pengajaran/pelatihan kepada peserta workshop (Sanjaya, 2013). Dapat dikatakan juga bahwa workshop yaitu memberi pengajaran/pelatihan kepada para peserta mengenai teori dan juga praktek. Fokus kegiatan adalah workshop penelitian tindakan kelas.

Workshop penelitian tindakan kelas (PTK) ini dilaksanakan dalam bentuk penyampaian materi secara komprehensif tentang kecakapan dan keterampilan menulis proposal penelitian tindakan kelas (PTK). Selanjutnya, pendampingan kepada peserta dalam menyusun rancangan penelitian tindakan kelas (PTK). Pendampingan ini diberikan selama pelaksanaan kegiatan workshop berlangsung. Selain itu, peserta diberikan kesempatan melakukan konsultasi. Adapun langkah-langkah pelaksanaan kegiatan workshop ini meliputi persiapan, pelaksanaan dan penutup.

1. Persiapan Kegiatan

Aktivitas yang dilakukan oleh tim pengabdian pada proses persiapan adalah: a) Koordinasi dengan mitra, Ketua forum MGMP Bahasa Inggris SMP kota Tarakan untuk menentukan jadwal pelaksanaan kegiatan dan alat-alat/bahan penunjang yang diperlukan di kegiatan, b) Menyusun jadwal workshop, c) Menentukan materi workshop, d) Menentukan narasumber workshop.

2. Pelaksanaan Kegiatan

Aktivitas yang dilaksanakan oleh tim pengabdian pada tahap pelaksanaan kegiatan adalah pemberian materi workshop PTK (teori dan praktek). Pada setiap penyampaian materi oleh narasumber, peserta diberi kesempatan melakukan dialog interaktif, diskusi dan Tanya-jawab. Sesuai dengan jadwal kegiatan, penyampaian materi PTK dilakukan di hari pertama kegiatan. Pada hari kedua dan ketiga, peserta diminta untuk latihan praktek menyusun proposal PTK sesuai dengan pembagian kelompoknya. Narasumber dibantu oleh fasilitator workshop melakukan pendampingan dan bimbingan selama kegiatan workshop PTK berlangsung.

3. Kegiatan penutup workshop

Aktivitas yang dilaksanakan pada tahap kegiatan penutup workshop adalah melaksanakan evaluasi kegiatan. Evaluasi ini dilaksanakan untuk memperoleh masukan, saran dari peserta kegiatan workshop. Saran dari peserta antara lain a) Kegiatan workshop PTK diperpanjang waktunya atau pertemuan ditambah, b) Melaksanakan workshop sejenis dalam waktu yang tidak terlalu lama untuk 
menjaga motivasi dan semangat guru, c) Membantu dan memfasilitasi kegiatan penyusunan artikel penelitian, d) Membantu dan memfasilitasi publikasi artikel pada jurnal ilmiah.

\section{Hasil dan Pembahasan}

1. Persiapan Kegiatan

Persiapan kegiatan dilakukan pada 20 Juli 2020, tim melakukan diskusi awal dengan ketua Forum MGMP (musyawarah guru mata pelajaran) bahasa Inggris SMP tentang kegiatan pengabdian workshop PTK. Selanjutnya ketua tim melakukan koordinasi penentuan jadwal pelaksanaan workshop PTK, tempat pelaksanaan workshop PTK, dan alatalat penunjang yang diperlukan pada kegiatan workshop PTK.

Hasil koordinasi dengan mitra (ketua Forum MGMP Bahasa Inggris SMP kota Tarakan) adalah kegiatan workshop PTK dilaksanakan pada 8 -10 Agustus 2020 bertempat di raung pertemuan SMP Negeri 1 Tarakan dan mitra berpartisipasi sebagai berikut: a) menyediakan tempat workshop PTK, b) menyediakan kursi, meja, papan tulis dan perlengkapan presentasi seperti LCD, dan c) menyiapkan perlengkapan sound system.

2. Pelaksanaan Kegiatan

Pelaksanaan kegiatan workshop dilakukan sesuai dengan tahapan persiapan. Pada tahap ini Tim pengabdian melaksanakan kegiatan workshop PTK, peserta yang terlibat dalam kegiatan workshop ini adalah 2 guru bahasa Inggris perwakilan dari setiap SMP negeri atau swasta dengan jumlah peserta 30 orang. Kegiatan workshop PTK dilaksanakan bertempat di ruang pertemuan SMP Negeri 1 Tarakan. Pelaksanaan kegiatan workshop PTK berlangsung dari 8 sampai 10 Agustus 2020 .

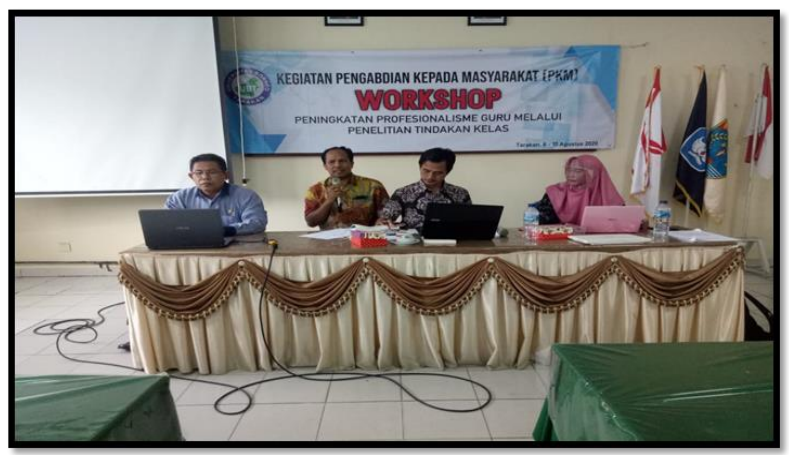

Gambar 1. Sambutan Wakil Dekan FKIP Universitas Borneo Tarakan

(Sumber: Dokumentasi, 2020)

Acara pembukaan kegiatan workshop PTK dihadiri oleh tim pengabdian, wakil dekan FKIP Universitas Borneo Tarakan, narasumber, ketua dan pengurus MGMP bahasa Inggris SMP. Dalam sambutan nya, ketua tim pengabdian menjelaskan kepada peserta dan workshop dan undangan tentang tujuan dan dasar serta teknis kegiatan. Wakil dekan FKIP universitas Borneo Tarakan dalam sambutannya menyampaikan apresiasi yang baik kepada tim pengabdian dan forum MGMP bahasa Inggris SMP kota Tarakan atas terlaksanaan kegiatan workshop PTK ini sebagai wujud nyata kemitraan. Harapannya pelaksanaan kegiatan tidak berhenti pada kegiatan workshop PTK ini. Semoga dikemudian hari terdapat kegiatan-kegiatan lainnya. Di samping itu wakil dekan FKIP Universitas Borneo Tarakan memberikan dukungan dan dorongan kepada guru untuk mengikuti workshop PTK yang diadakan oleh tim pengabdian FKIP Universitas Borneo Tarakan dengan sebaik-baiknya. Ketua MGMP dalam sambutannya mengucapkan terima kasih kepada tim pengabdi dan menyambut kegiatan workshop PTK dengan sangat antusias dan juga memberikan motivasi kepada guru-guru agar mengikuti kegiatan workshop dengan sebaik-baiknya. Harapannya persoalan guru yang dihadapi dalam penyusunan karya tulis ilmiah dapat diatasi dengan baik. Selanjutnya ketua forum MGMP membuka secara resmi kegiatan workshop PTK. Kemudian acara pembukaan ditutup dengan doa yang disampaikan oleh wakil peserta workshop. 


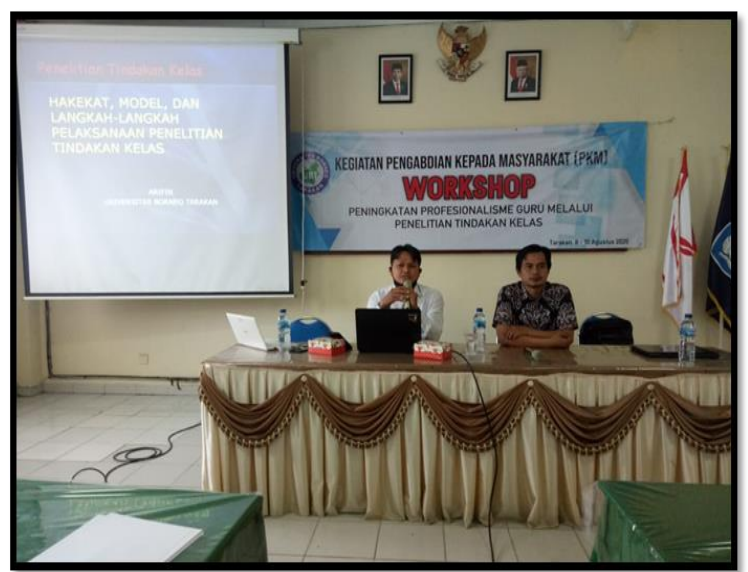

Gambar 2. Penyampaian Materi oleh Narasumber (Sumber: Dokumentasi, 2020)

Dalam pelaksanaan workshop PTK, pada sesi praktik peserta dilatih dan dibimbing oleh narasumber dibantu oleh fasilitator dalam penyusunan rancangan PTK. Adapun materimateri workshop yang disampaikan oleh narasumber adalah sebagai berikut:

a) Hakekat dan model penelitian tindakan kelas

b) Langkah-langkah PTK

c) Kajian literatur/teori untuk penelitian

d) Pengembangan instrumen penelitian tindakan kelas

e) Teknik penyusunan proposal PTK

f) Jenis publikasi ilmiah dan bukti fisiknya.

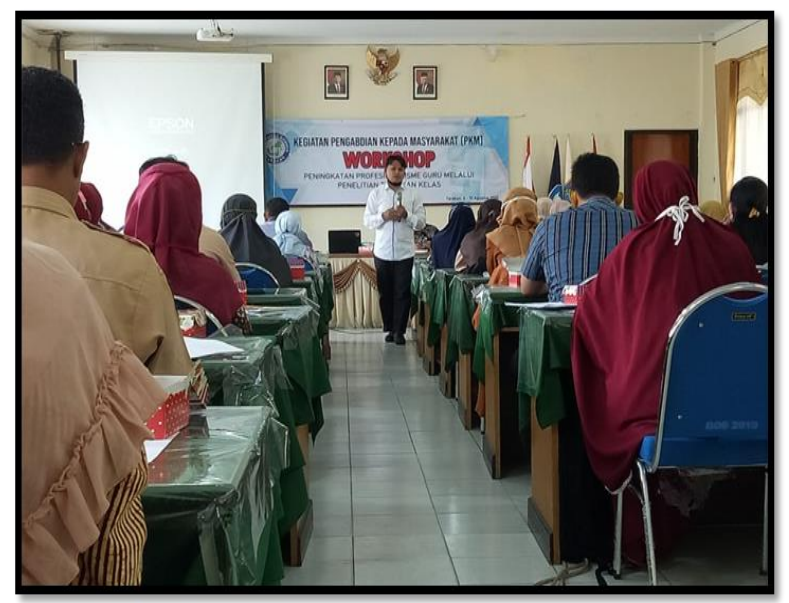

Gambar 3. Narasumber diskusi interaktif dengan peserta Workshop PTK

(Sumber: Dokumentasi, 2020)

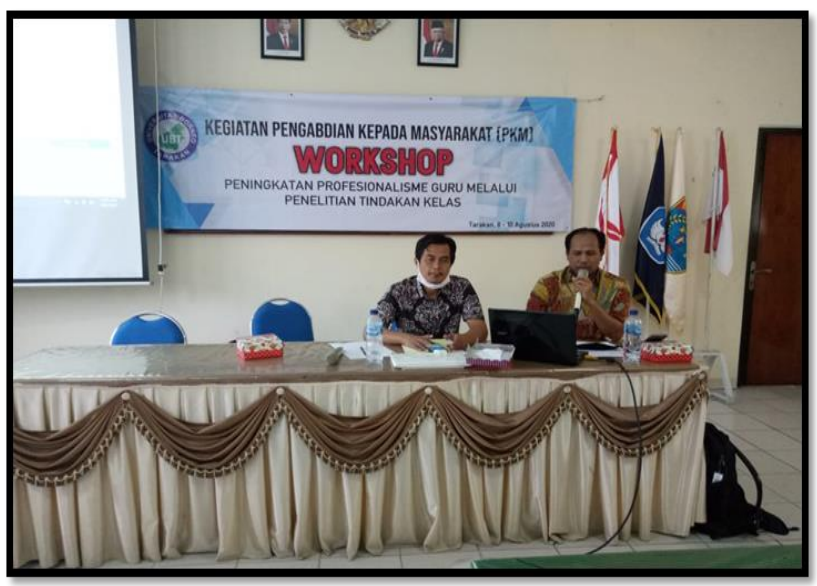

Gambar 4. Penyampaian Materi oleh Narasumber (Sumber: Dokumentasi, 2020)

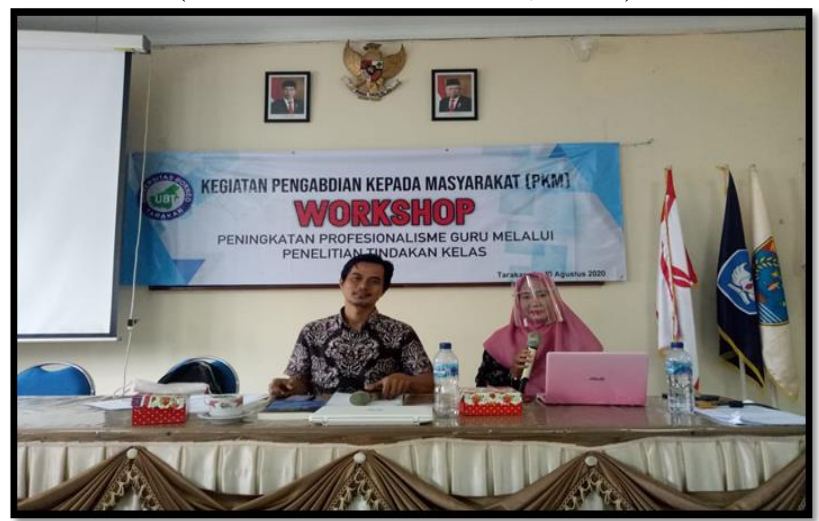

Gambar 5. Penyampaian Materi oleh Narasumber (Sumber: Dokumentasi, 2020)

Pada setiap penyampaian materi oleh narasumber, peserta diberi kesempatan melakukan dialog interaktif, diskusi dan Tanyajawab. Sesuai dengan rundown kegiatan, penyampaian materi PTK dilakukan di hari pertama kegiatan.

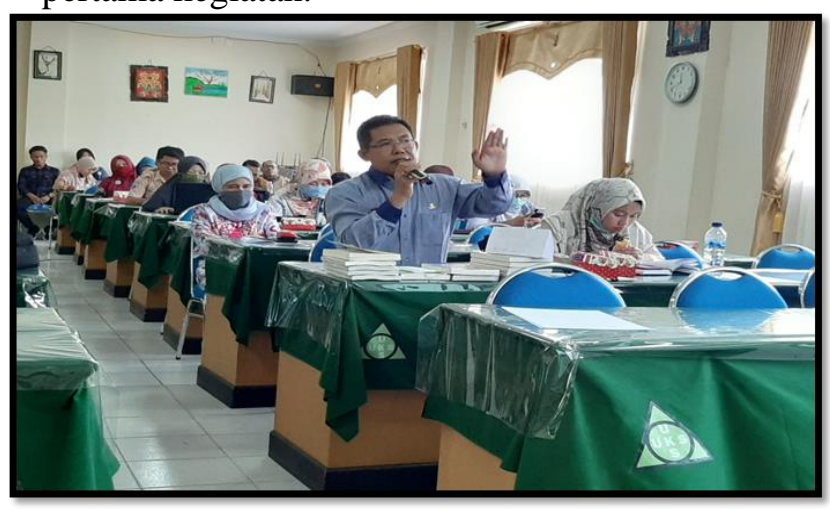

Gambar 6. Penyampaian Pendapat dan Pertanyaan Peserta Workshop

(Sumber: Dokumentasi, 2020) 


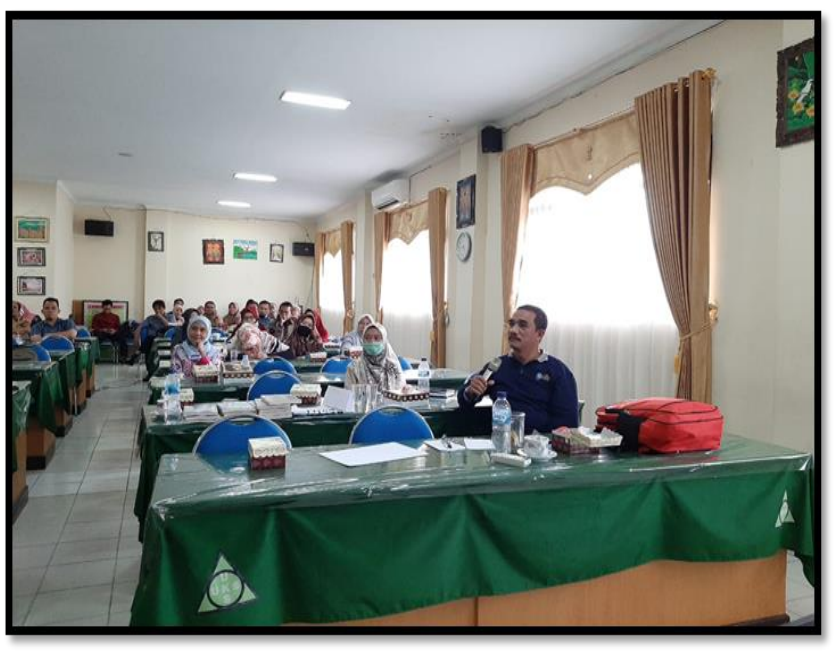

Gambar 7. Penyampaian pendapat dan pertanyaan peserta workshop

(Sumber: Dokumentasi, 2020)

Pada hari kedua dan hari ketiga, peserta diminta untuk latihan praktek menyusun proposal PTK di kelompoknya masing-masing. Narasumber dan fasilitator melakukan pendampingan dan bimbingan selama peserta melakukan praktik menyusun rancangan PTK. Setiap kelompok diberi kesempatan untuk mempresentasikan hasil rancangan PTK agar memperoleh saran perbaikan dari peserta workshop.

\section{Evaluasi Kegiatan}

Evaluasi kegiatan dilaksanakan dengan menerima langsung masukan, saran dari para peserta kegiatan workshop. Saran dari peserta antara lain a) supaya kegiatan workshop PTK diperpanjang waktunya atau pertemuan ditambah, b) agar melaksanakan workshop sejenis dalam waktu yang tidak terlalu lama untuk menjaga motivasi dan semangat guru yang telah meningkat ini, c) agar membantu dan memfasilitasi penerbitan artikel penelitian pada jurnal ilmiah.

Hasil evaluasi tim pengabdian terhadap peserta dan intern tim antara lain: a) kompetensi guru dalam penelitian tindakan kelas masih bervariasi. Ada guru yang sudah mempunyai kompetensi yang baik bahkan ada seorang guru yang sudah menjadi bagian dari tim penilai PAK guru. Ada juga guru yang masih rendah kompetensi nya dalam penelitian, b) Beberapa guru masih kurang dalam penguasaan teknologi informasi, c) Beberapa guru masih belum keluar dari zona nyaman, artinya guru tersebut masih puas dengan keadaanya sekarang, d) para guru masih tersita waktunya dalam pekerjaan administrasi penyusunan silabus, RPP dan administrasi sekolah lainnya, e) tim perlu menyempurnakan materi,melengkapi dengan contoh-contoh nya, f) bimbingan perlu disempurnakan seperti bimbingan terstruktur.

\section{Kesimpulan}

Kegiatan workshop penelitian tindakan kelas terlaksana dengan baik dan lancar. Guru-guru mengikuti kegiatan ini dengan baik dan serius. Kegiatan workshop ini memberikan manfaat bagi guru dalam mengatasi pemasalahan dalam menyusun proposal karya tulis ilmiah (PTK) yang dapat digunakan untuk memenuhi persyaratan kenaikan pangkat dan meningkatnya professionalme guru. Diakhir kegiatan, hanya sebagian kecil guru yang memiliki kemampuan membuat proposal PTK. Sebagian besar guru masih belum terbiasa melakukan PTK. Namun demikian motivasi para guru dalam melakukan PTK meningkat. Oleh karena itu, diperlukan intervensi dari pemangku kepentingan di bidang pendidikan agar profesionalisme guru melalui penelitian dapat terwujud.

\section{Ucapan Terima Kasih}

Dengan selesainya pengabdian ini, kami mengucapkan terima kasih yang tak terhingga atas dukungan semua pihak sehingga kegiatan workshop penelitian tindakan kelas dapat terlaksana dengan baik. Secara khusus, kami mengucapkan terima kasih kepada Universitas Borneo Tarakan yang telah memberikan dana pengabdian, dan juga ketua Forum Musyawarah Guru Mata Pelajaran (MGMP) serta guru-guru bahasa Inggris SMP di kota Tarakan dan kepala sekolah menengah pertama negeri 1 Tarakan yang telah menyediakan tempat dan fasilitas pendukung workshop ini.

\section{Daftar Pustaka}

Arikunto, S (2010). Penelitian Tindakan Kelas. Jakarta: PT Bumi Aksara dan 
Kompetensi Guru. Jakarta: Ditjen Dikdasmen

Dharmayasa, I., Arya, P., \& Vijaya, D. P. (2020). Penulisan Penelitian Tindakan Kelas (Ptk) Untuk Meningkatkan Profesionalisme Guru SD. Proceeding Senadimas Undiksha. Hal, 990-997.

Peraturan Menteri Pendidikan Nasional Nomor 16 Tahun 2007. Standar Kualifikasi Akademik

Prenada Media.

Sanjaya, Wina. (2013). Penelitian Pendidikan: Jenis, Metode dan Prosedur. Jakarta : Kencana Sumardi. (2016). Pengembangan Profesionalisme Guru Melalui MGMP; Model dan Implementasinya untuk meningkatkan kinerja Guru. Yogyakarta: Deepublisher.

Trihantoyo, S., Andari, S., \& Haq, M. S. (2021). Coaching Clinic Peningkatan Profesional Guru melalui Karya Ilmiah bagi Guru Sekolah Dasar. Pucuk Rebung: Jurnal Pengabdian Kepada Masyarakat, 1(2), 40-53. 